\title{
The perceptions and experiences of osteopathic treatment among cancer patients in palliative care:
}

M. Filbet $^{1}$, A. Steel ${ }^{2}$, T. Monsarrat ${ }^{1}$, C. Tricou $^{1}$.

\section{A qualitative study}

${ }_{1}^{1}$ service de soins palliatifs Pavillon $1 K$ CHLS CHU de Lyon, Medecine palliative, Pierre-Benite, France.

${ }^{2}$ Endeavour College of Natural Health, Australian Research Centre in Complementary and Integrative Medicine University of Technology, Sydney, Australia

\section{Introduction:}

In France, recently, osteopathy is acknowledged as a distinct health profession as well as the required training standards . In our PC service ( in and out patients)an osteopathic treatment is proposed to our cancer patients for more that 10 years .

\section{Objectives}

explore the perceptions and experiences of cancer patients receiving osteopathic treatment as a complementary therapy when it is used in addition to conventional treatment for cancer pain.

\section{Methods}

This qualitative study employed semi structured interviews of cancer patients iwho received treatment from an osteopath alongside their conventional cancer treatment. We analyzed data using grounded theory

\section{Results}

We interviewed 16 patients until data saturation.

Population Characteristics :

\begin{tabular}{|c|c|c|}
\hline Age (SD) & & $56,25(15)$ \\
\hline Gender & Male & $9(56,25)$ \\
\hline \multirow{3}{*}{$\begin{array}{l}\text { Performance } \\
\text { status (PS) }\end{array}$} & 0 & $3(18,75)$ \\
\hline & 1 & $2(12,5)$ \\
\hline & 2 & $11(68,50)$ \\
\hline \multirow{6}{*}{ Cancer type } & breast & $4(25)$ \\
\hline & lung & $3(18,75)$ \\
\hline & blood & $3(18,75)$ \\
\hline & urologic & $3(18,75)$ \\
\hline & $\begin{array}{l}\text { Head and } \\
\text { neck }\end{array}$ & $2(12,5)$ \\
\hline & $\begin{array}{l}\text { melanom } \\
\mathrm{a}\end{array}$ & $1(6,25)$ \\
\hline $\begin{array}{l}\text { Average } \\
\text { opioide } \\
\text { doase MEDD }\end{array}$ & & $93,75 \mathrm{MG}(184,28)$ \\
\hline
\end{tabular}

LOW AWARNESS AND HIGHT MISCONCEPTIONS
" bone craking » "its always very gentle "
the osteopatic diagnosis
Able to name the cause of the pain " he make the pain less dramatic,
he explain it "

he explain it »

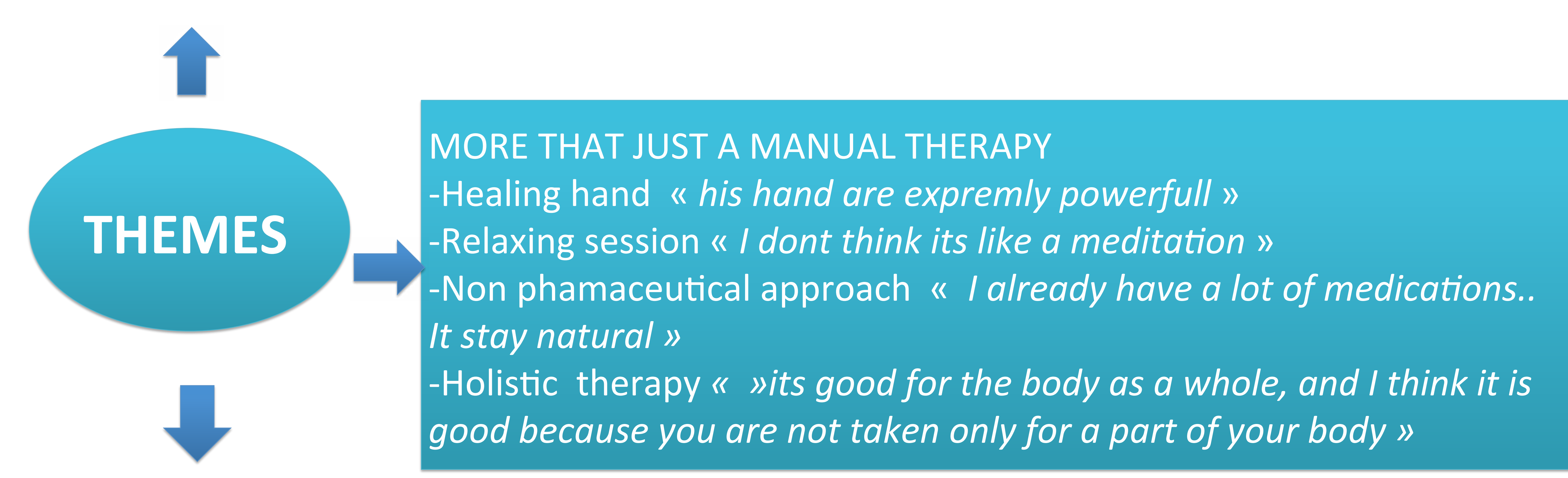

\section{Conclusions}

The findings of this study provides preliminary data which suggests, when delivered alongside existing medical care, osteopathy may have health benefits for patients with complex conditions such as cancer. 